\title{
Rho Signaling Pathway Targeted to Promote Spinal Cord Repair
}

\author{
Pauline Dergham, ${ }^{1}$ Benjamin Ellezam, ${ }^{1}$ Charles Essagian, ${ }^{1}$ Hovsep Avedissian, ${ }^{2}$ William D. Lubell, ${ }^{2}$ and \\ Lisa McKerracher ${ }^{1}$
}

Départements de ${ }^{1}$ Pathologie et Biologie Cellulaire and ${ }^{2}$ Chimie, Université de Montréal, Montréal, Québec, H3T 1J4, Canada

The Rho signaling pathway regulates the cytoskeleton and motility and plays an important role in neuronal growth inhibition. Here we demonstrate that inactivation of Rho or its downstream target Rho-associated kinase (ROK) stimulated neurite growth in primary cells of cortical neurons plated on myelin or chondroitin sulfate proteoglycan substrates. Furthermore, treatment either with C3 transferase (C3) to inactivate Rho or with Y27632 to inhibit ROK was sufficient to stimulate axon regeneration and recovery of hindlimb function after spinal cord injury (SCl) in adult mice. Injured mice were treated with a single injection of Rho or Rho-associated kinase inhibitors delivered in a protein adhesive at the lesion site. Treated animals showed long-distance regeneration of anterogradely labeled corticospinal axons and increased levels of GAP-43 mRNA in the motor cortex. Behaviorally, inactivation of Rho pathway induced rapid recovery of locomotion and progressive recuperation of forelimb-hindlimb coordination. These findings provide evidence that the Rho signaling pathway is a potential target for therapeutic interventions after spinal cord injury.

Key words: Rho GTPase; Rho-associated kinase; C3; Y27632; corticospinal tract; regeneration; $B B B$ behavior scale; GAP-43; mouse
Mammalian neurons do not regenerate successfully after lesion. This is explained in part by myelin-derived inhibition (Caroni and Schwab, 1988; McKerracher et al., 1994; Mukhopadhyay et al., 1994; Chen et al., 2000) and the formation of a glial scar expressing inhibitory molecules (Snow et al., 1990; McKeon et al., 1991; Asher et al., 2000). However, numerous studies in animal models using methods designed to overcome the effect of growth inhibitory proteins have confirmed the regenerative potential of the injured spinal cord. These methods include the use of antibodies (Schnell and Schwab, 1990; Huang et al., 1999), peripheral nerve grafts (Cheng et al., 1996), transplantation of cells into the lesion site (Howland et al., 1995; Rapalino et al., 1998; Liu et al., 1999; McDonald et al., 1999; Ramon-Cueto et al., 2000) and limiting the formation of the glial scar (Davies et al., 1999; Moon et al., 2000).

The failure of regeneration in the adult CNS may also be caused by changes occurring in mature neurons (Li et al., 1995, 1996; Shen et al., 1999; Cai et al., 2001). Another approach to stimulate regeneration has been to target neurite growth signaling. For example, different neurotrophin treatments have increased the ability of neurons in adult CNS to regenerate and stimulate both axonal growth and sprouting after injury (Schnell et al., 1994; Sawai et al., 1996; Blesch and Tuszynski, 1997; Weidner et al., 1999; Coumans et al., 2001). Neurotrophins are known to delay apoptosis, prevent atrophy of axotomized neurons, and enhance the expression of growth-associated genes

\footnotetext{
Received Dec. 3, 2001; revised May 6, 2002; accepted May 8, 2002.

This work was supported by the Canadian Institutes of Health Research (CIHR), a Barbara Turnbull Foundation-CIHR Scholarship (P.D.), and a Fonds de la Recherche en Santé (FRSQ) scholarship (B.E.). L.M. is a Chercheur Boursier Senior of the FRSQ. We thank Dr. Sam David for valuable discussions on spinal cord surgery and anterograde labeling. We thank Dr. Dana Lasko for comments on this manuscript and Charles Essagian for expert technical help. We gratefully acknowledge Maxime Lehmann for help with the synthesis of C3.

Correspondence should be addressed to Dr. Lisa McKerracher, Département de Pathologie et Biologie Cellulaire, Université de Montréal, CP 6128, Succursale Centre-Ville, Montréal, Quebec, H3C 3J7, Canada. E-mail: mckerral@patho.umontreal.ca.

Copyright (C) 2002 Society for Neuroscience $0270-6474 / 02 / 226570-08 \$ 15.00 / 0$
}

(Fournier et al., 1997; Kobayashi et al., 1997; Bregman et al., 1998; Broude et al., 1999). Recent data suggest that neurotrophins might stimulate regeneration by increasing neuronal cAMP levels to overcome inhibitory signaling (Cai et al., 1999). Therefore, the decreased ability of the mature CNS to regenerate after injury may result from both the intrinsic properties of adult neurons and the extracellular inhibitory environment.

The Rho GTPase is a key intracellular regulator of cytoskeletal dynamics and cell motility (Hall, 1998). Rho is activated when growth cones collapse in response to chemorepulsive factors (Tigyi et al., 1996; Jin and Strittmatter, 1997; Kuhn et al., 1999; Wahl et al., 2000), and inhibiting Rho promotes neurite outgrowth in the presence of myelin (Jin and Strittmatter, 1997; Lehmann et al., 1999). Recently, Rho has been shown to regulate apoptosis (Liu et al., 2001; Trapp et al., 2001). An enzyme from Closteridium botulinum, C3 transferase (C3), blocks Rho function by ADP ribosylation of the effector domain (Dillon and Feig, 1995). Y27632 inhibits Rho-associated kinase (ROK), a serinethreonine protein kinase that is activated by Rho (Ishizaki et al., 1997; Uehata et al., 1997). Inactivation of ROK with Y27632 promotes neurite outgrowth (Katoh et al., 1998; Bito et al., 2000), but it is not known whether it is sufficient to block growth inhibition as was shown for inactivation of Rho (Lehmann et al., 1999). In the present study, we compare inactivation of Rho or ROK to promote axon growth on inhibitory substrates. We further study in fully adult mice whether inactivation of the Rho signaling pathway promotes axon regeneration and functional recovery after spinal cord injury (SCI). Animals treated to inactivate the Rho signaling pathway show significant improvement in locomotion by open field testing. Thus, inactivation of the Rho signaling pathway is an effective method to improve outcome after SCI.

\section{MATERIALS AND METHODS}

Cell culture. Primary cortical neurons were isolated from embryonic day (E) 15-E18 rat fetuses. The cortex was cut into small pieces into $\mathrm{Ca}^{2+}$ 
and $\mathrm{Mg}^{2+}$-free HBSS, $0.3 \mathrm{M}$ HEPES buffer, $\mathrm{pH}$ 7.3, and penicillin/ streptomycin, and then dissociated with $0.25 \%$ trypsin, $0.1 \%$ DNase at $37^{\circ} \mathrm{C}$ for $15 \mathrm{~min}$. The dissociated cells were washed and diluted to $2 \times 10^{5}$ cells per milliliter in minimal essential media (Invitrogen, Burlington, ON), N2 supplement (Invitrogen), 5\% fetal bovine serum, 1\% ovalbu$\mathrm{min}$, and $1 \mathrm{~mm}$ pyruvate. Cells were then triturated with $25 \mu \mathrm{g} / \mathrm{ml} \mathrm{C} 3$ or buffer, or with 31 or $3.1 \mu \mathrm{M}$ Y27632. Cells were plated in eight-well chamber slides coated with $25 \mu \mathrm{g} / \mathrm{ml}$ poly-L-lysine or with test substrates. Myelin substrates were made by coating with $8 \mu \mathrm{g}$ purified bovine brain myelin dried overnight at room temperature. Chondroitin sulfate proteoglycan (CSPG) substrates were made by incubating $0.5 \mu \mathrm{g} / \mathrm{ml}$ mixed CSPG solution (Chemicon, Temecula, CA) overnight in poly-L-lysinecoated chamber slides. Mixed substrate was made by coating and drying $8 \mu \mathrm{g}$ of myelin in $150 \mu \mathrm{l}$ of CSPG solution. The plates were fixed with $4 \%$ paraformaldehyde and $0.5 \%$ gluteraldehyde after 12,24 , or $48 \mathrm{hr}$, and neurons were identified by immunocytochemistry using a $\beta$ III-tubulin antibody (Sigma, Oakville, ON). The longest neurite per neuron was measured on an average of 400 cells per experiment with a minimum of three experiments per condition. Doses for C3 and Y27632 were chosen on the basis of previous experiments (Lehmann et al., 1999; Bito et al., 2000; M. Winton and L. McKerracher, unpublished observations)

Preparation of recombinant $\mathrm{C} 3$ and Y27632. Recombinant C3 exoenzyme was prepared as a glutathione $S$-transferase-C3 fusion protein and stored at $-80^{\circ} \mathrm{C}$ (Lehmann et al., 1999). Y27632 was synthesized from $\alpha$-methylbenzylamine and exhibited identical ${ }^{1} \mathrm{H}$ and ${ }^{13} \mathrm{C}$ nuclear magnetic resonance spectra as reported in United States Patents 4,997,834 and 5,478,838. Before in vivo use, the activity of C3 and Y27632 was tested in tissue culture with retinal neurons plated on myelin substrates (Lehmann et al., 1999).

Spinal cord injury and delivery of Rho and Rho-kinase inhibitors. BALB-c female mice $(n=70)$ of $\sim 20$ gm were anesthetized with 0.4 $\mathrm{ml} / \mathrm{kg}$ hypnorm and $5 \mathrm{mg} / \mathrm{kg}$ diazepam. A segment of the thoracic spinal cord was exposed using fine rongeurs to remove the bone, and a dorsal over-hemisection was made at T7. Fine scissors were used to cut the dorsal part of the spinal cord, which was cut a second time with a fine knife to ensure that the lesion extended past the central canal. A fibrin adhesive delivery system was prepared using a Tisseel VH kit (ImmunoAG, Vienna, Austria). According to manufacturer's instructions for slow polymerization, lyophilized fibrinogen was reconstituted in an aprotinin solution, thrombin was reconstituted in a calcium chloride solution, and both solutions were warmed to $37^{\circ} \mathrm{C}$. Fifty microliters of $1 \mathrm{mg} / \mathrm{ml} \mathrm{C} 3$ or Y27632 were added to $25 \mu \mathrm{l}$ of the thrombin solution. This was mixed with $25 \mu$ lof the fibrinogen solution just before application to the spinal cord to allow infiltration of the mixture into the lesion site before polymerization. In some C3-treated animals and in all Y27632-treated animals, $10 \mu \mathrm{l}$ of the $1 \mathrm{mg} / \mathrm{ml}$ solution was applied to the lesion site immediately after the cord was cut. As controls, a second group of animals received fibrin adhesive with buffer, and a third group was left untreated. C3-containing collagen gels were formed as follows. C3 was lyophilized (40 $\mu \mathrm{g}$ per mouse) and then reconstituted in $10 \mu \mathrm{l}$ of $7.5 \%$ $\mathrm{NaHCO}_{3}$, and then $25 \mu \mathrm{l}$ of $0.7 \mathrm{mg} / \mathrm{ml}$ rat tail collagen was added. As with fibrin, $10 \mu \mathrm{l}$ of $\mathrm{C} 3$ was added to the lesion cavity before the C3-containing collagen gel was applied. For retransections 3 weeks after SCI, the spinal cords were cut at T6 as described above, and the animals were tested using the Basso-Beattie-Bresnahan (BBB) locomotor rating scale on days 1,2, and 6 after the second surgery.

Anterograde labeling. Three weeks to 3 months after injury, corticospinal tract (CST) fibers were labeled by injection of the anterograde tracer wheat germ agglutinin-horse radish peroxidase (WGA-HRP) into the motor cortex as described (Huang et al., 1999). Two days later, the animals were perfused transcardially with saline and then $4 \%$ paraformaldehyde, and the spinal cords and brains were removed. Serial longitudinal cryostat sections of the spinal cord were cut at $30 \mu \mathrm{m}$, reacted for HRP (Huang et al., 1999), and counterstained with neutral red. Measurement of axon regeneration was assessed independently by two reviewers. Lesion depth was assessed by measuring the depth of damaged tissue in the spinal cord as a percentage of total spinal cord width.

In situ hybridization. GAP-43 mRNA was detected by in situ hybridization on coronal cryostat sections through the motor cortex of mice treated with PBS $(n=2)$ or $\mathrm{C} 3(n=3)$. In situ hybridization was performed as described previously (Fournier et al., 1997) with an ${ }^{35} \mathrm{~S}$ labeled GAP-43 cRNA probe derived from a plasmid provided by Dr. Pate Skene (Duke University Medical Center) (Basi et al., 1987). After the in situ hybridization procedure, sections were Nissl stained and bright-field and dark-field digital micrographs were taken. On the basis of
Nissl staining and retrograde labeling of motor cortex by Fluorogold in previous animals, a region was circled on bright-field micrographs to include axotomized layer V neurons. Corresponding dark-field micrographs were black and white inverted and thresholded in Northern Eclipse (Empix imaging, Mississauga, ON), and autoradiographic grain clusters $>30$ pixels in size were counted. Background-corrected grain cluster densities were calculated on 4-10 sections per animal using the following formula: [(number of counted grain clusters in circled region/ area of circled region)/(number of counted grain clusters in background/ area of background sampled].

Behavioral testing. Behavioral recovery was assessed for 1 month after SCI in an open field environment by the BBB method (Basso et al., 1995). We modified the 21 point BBB scale to a 17 point score because mice do not exhibit differences in toe drag that can be monitored visually. Thus, scale points 16,17 , and 18 were removed from the scale. Mice raise their tails early in their recovery, and score 19 for tail up position was removed, leaving a 17 point total score. The mouse modified BBB score was as follows: (0) no observable hindlimb (HL) movement; (1) slight movement of one or two joints; (2) extensive movement of one joint and/or slight movement of one other joint; (3) extensive movement of two joints; (4) slight movement of all three joints of the HL; (5) slight movement of two joints and extensive movement of the third; (6) extensive movement of two joints and slight movement of the third; (7) extensive movement of all three joints of the HL, walking with little/no weight support; (8) extensive movement of all three joints, walking with weight support; (9) frequent to consistent dorsal stepping with weight support; (10) frequent plantar stepping with weight support; (11) consistent plantar stepping with weight support, no coordination; (12) consistent plantar stepping with consistent weight support, occasional forelimb (FL)-HL coordination; (13) consistent plantar stepping with consistent weight support, frequent FL-HL coordination; (14) consistent plantar stepping with consistent weight support, consistent FL-HL coordination; predominant paw position during locomotion is rotated internally or externally, or consistent FL-HL coordination with occasional dorsal stepping; (15) consistent plantar stepping with consistent weight support, consistent FL-HL coordination; predominant paw position is parallel to the body; frequent to consistent curled toes, trunk instability; (16) consistent plantar stepping with consistent weight support, consistent FL-HL coordination; predominant paw position is parallel to the body, flat toes, some trunk instability; (17) consistent plantar stepping with consistent weight support, consistent FL-HL coordination; predominant paw position is parallel to the body, flat toes and consistent stability in the locomotion. For scoring, each animal was videotaped for $3 \mathrm{~min}$, and two reviewers participated. In the late phase of recovery, the BBB score was determined from sequences of four steps or more from digitized videos projected on a computer screen at one-fourth speed. Detailed patterns of front paw and foot placements were assessed, as shown in Figure 5, $F$ and $G$, for untreated $(n=6)$ and C3-treated $(n=6)$ animals.

\section{RESULTS

Inactivation of Rho or ROK promotes growth of
primary neurons plated on complex
inhibitory substrates

We tested first whether treatment of primary cortical neurons with C3 or with Y27632 was sufficient to stimulate growth on complex inhibitory substrates typical of the glial scar and white matter. Neurons plated on different test substrates were examined at 12,24 , and $48 \mathrm{hr}$, and similar results were observed at all time points. Neurons plated on CSPG, purified myelin, or a mixture of both did not extend long neurites and had a rounded shape (Fig. $1 A, B$ ). After treatment with C3 (Fig. 1C) or Y27632 (Fig. 1D), neurons were able to extend neurites. Measurements at $24 \mathrm{hr}$ showed that treatment with either C3 or Y27632 significantly increased the length of neurites compared with untreated cells plated on myelin, CSPG, or mixed myelin/CSPG substrates (Fig. $1 A$ ). Quantitation at $12 \mathrm{hr}$ showed similar results (data not shown), and at $48 \mathrm{hr}$ growth of treated neurons was too extensive to measure neurite length. C3 was significantly better than Y27632 in promoting neurite growth $(t$ test; $p<0.05)$. These results demonstrate that inactivation of Rho or inhibition of ROK 
A

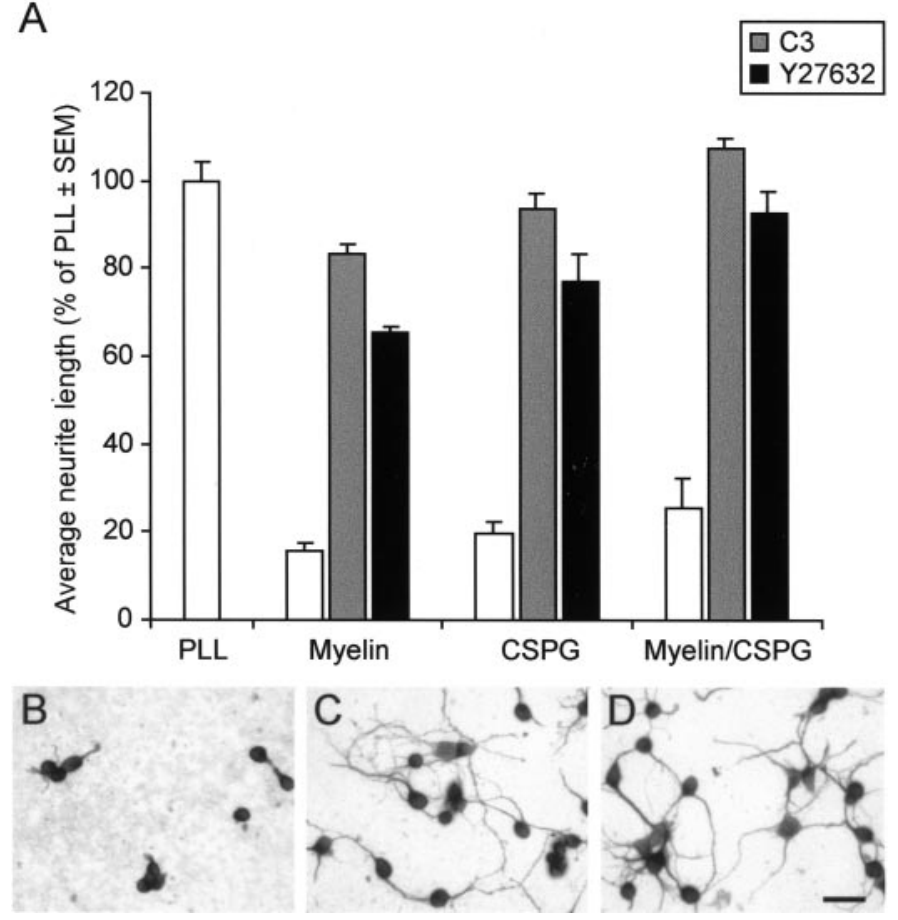

Figure 1. Effect of Rho antagonist C3 or Rho-associated kinase inhibitor Y27632 on neurite outgrowth of primary cortical neurons plated on inhibitory substrates. $A$, Neurite outgrowth was analyzed quantitatively by measuring the longest neurite per cell $24 \mathrm{hr}$ after plating on poly-L-lysine, myelin, CSPG, or mixed substrates and treatment with buffer (white), 25 $\mu \mathrm{g} / \mathrm{ml} \mathrm{C} 3$ (gray), or $31 \mu \mathrm{M}$ Y27632 (black). Differences between treated and untreated cells were significant on all test substrates $(t$ test; $p<0.05)$. $B-D$, Representative micrographs of cortical neurons plated on mixed inhibitory substrates either untreated $(B)$ or treated with $\mathrm{C} 3(C)$ or Y27632 (D). Scale bar, $25 \mu \mathrm{m}$.

stimulates cortical neurons to extend neurites on complex growth inhibitory substrates.

\section{Treatment of injured spinal cord promotes long-distance regeneration}

To assess the potential of Rho inactivation to treat SCI, we cut the spinal cord of adult mice at $\mathrm{T} 7$ by a dorsal over-hemisection (Huang et al., 1999). We tested C3 by local delivery either in collagen or in a fibrin adhesive that polymerizes in vivo several seconds after injection, because both matrices have been reported to support tissue repair (Joosten et al., 1995; Herbert et al., 1998). We used the fibrin adhesive to test Y27632 because of favorable results with $\mathrm{C} 3$ (see below). Anterograde tracing with WGAHRP of CST, a tract often used to study histological regeneration, was used to assess fiber growth in six groups of animals: animals treated with fibrin plus C3 $(n=13)$, collagen plus C3 $(n=12)$, fibrin plus Y27632 $(n=5)$, fibrin alone $(n=10)$, collagen alone $(n=7)$, and SCI with no treatment $(n=13)$ (Fig. 3). All sections were counterstained with neutral red to verify that lesions extended past the central canal (Fig. 2I). A quantitative analysis of lesion depth showed no significant differences between treated and control groups (one-way ANOVA). Without C3 or Y27632 treatment, transected CST axons retracted back from the site of lesion by $\sim 300 \mu \mathrm{m}$ (Fig. $2 H$ ), although in animals treated with fibrin alone some regenerative sprouts did extend from the retracted bundle (Fig. $2 G$ ). Application of $\mathrm{C} 3$ to the injured spinal cord elicited extensive sprouting into the dorsal white matter and the lesion scar (Fig. 2A,C,E). Treated animals with Y27632 showed regenerative sprouting into the dorsal white matter and toward the lesion site (data not shown). To assess axons distal to the lesion site, the distance of the longest axon was measured. Axons were found up to $12 \mathrm{~mm}$ from the lesion site in C3-treated animals and up to $3 \mathrm{~mm}$ from the lesion site in Y27632-treated animals (Fig. 3), whereas buffer-treated animals showed retraction from the lesion site. Therefore, after treatment with $\mathrm{C} 3$ or Y27632, axons were found to extend past the lesion into the distal white matter. These axons have a twisted course of growth typical of regenerated axons (Figs. 2D,F). Although neutral red staining showed lesions extended past the central canal (Fig. 2I), these experiments alone cannot rule out the possibility that secondary damage was reduced after injury. This could arise in the damaged CNS because C3 has neuroprotective effects (Liu et al., 2001; Trapp et al., 2001), in addition to promoting growth on inhibitory substrates (Fig. 1).

\section{Effect of C3 on the expression of GAP-43 mRNA in the motor cortex of spinal cord injured animals}

After thoracic spinal cord lesion, only axons that regenerate long distances show upregulation of GAP-43 mRNA expression (Ferandes et al., 1999). To confirm the growth response and the long-distance regeneration after Rho inactivation, we examined the pattern of GAP-43 mRNA expression in the motor cortex (Fig. $4 A, B)$ of animals 1 month after CST transection with or without treatment with $\mathrm{C} 3$. In situ hybridization using ${ }^{35} \mathrm{~S}$-labeled riboprobes on coronal brain sections revealed high levels of GAP-43 mRNA expression in neurons of the motor cortex of C3-treated animals (Fig. 4D), whereas untreated animals showed GAP-43 signal similar to background (Fig. 4C). Quantitation of grain cluster densities in motor cortex showed significant upregulation of GAP-43 mRNA (Fig. $4 E$ ). These results indicate that C3 treatments elicit changes in gene expression consistent with axon regeneration.

\section{Behavioral testing}

To test functional recovery after SCI and C3 or Y27632 treatment, we measured HL motor function using the BBB locomotor rating scale (Basso et al., 1995) $(n=37$ animals). Because a toe clearance phase cannot be evaluated in recuperating mice, we modified the rating to a 17 point scale (see Materials and Methods). Twenty-four hours after surgery, control mice were paraplegic (Fig. $5 A$ ) and moved by pulling themselves forward with their forelimbs (Fig. 5B). Mice treated with C3 or Y27632 showed a remarkable recovery within $24 \mathrm{hr}$ (Fig. $5 A$ ), already walking with weight support (Fig. 5A,C) (movie 1; available at www.jneurosci.org). Although this early recovery is too rapid to be explained by long-distance regeneration, possible mechanisms include local reorganization of central pattern generator circuitry (Giménez y Ribotta et al., 2000) that may include sprouting from undamaged ventral fibers or interneurons, pharmacological activation of neurotransmitter receptors (Rossignol et al., 2000), or neuroprotection (C. Dubreuil, M. Winton, F. Yang, P. Morley, L. McKerracher, unpublished observations). Mice that had received C3 or Y27632 treatment continued to recover over the 1 month period of observation and exhibited HL-FL coordination (Fig. $5 E, G)$ (movie 2; available at www.jneurosci.org). By contrast, the average recovery plateau for untreated animals was limited to unstable walking without HL-FL coordination (Fig. 5D,F) (movie 2). Retransection of the spinal cord at 3 weeks $(n=8)$ eliminated any difference between the C3-treated $(n=5)$ and control $(n=3)$ animals (BBB at day 6, 7.6 vs 7.3, respectively). 

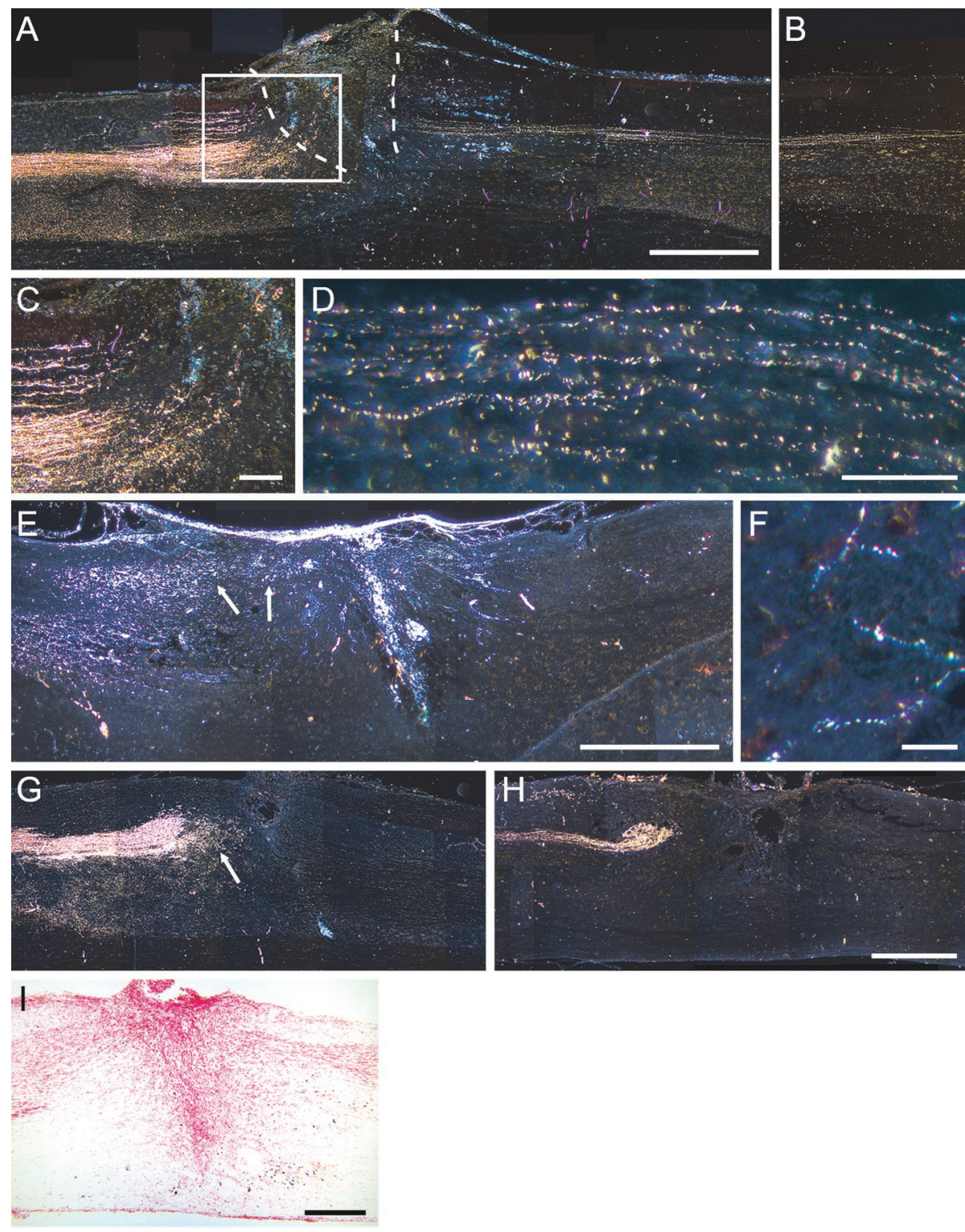

\section{DISCUSSION}

The failure of axon regeneration in the spinal cord is attributable, at least in part, to the growth inhibitory properties of white matter and the lesion site. The Rho signaling pathway is known to be important both for the cell response to growth inhibition (Lehmann et al., 1999) and for neuroprotection (Trapp et al., 2001), and growth-inhibitory substrates activate Rho (M. Winton and L. McKerracher, unpublished observations). We report here that inactivation of either Rho or Rho kinase is sufficient to allow axon growth on inhibitory substrates and leads to improved recovery after SCI. C3 ribosylates asparagine 41 in the effector domain to inactivate Rho (Sekine et al., 1989); Y27632 inhibits the kinase activity of ROK by competing with ATP for binding to the kinase (Ishizaki et al., 1997; Uehata et al., 1997). Our studies target these two different parts of the Rho signaling pathway to demonstrate the importance of Rho signaling for CNS repair. Both C3 and Y27632 promoted axon growth, but C3 was more effective than Y27632. The difference between the effects of C3 and Y27632 suggest the presence of other effectors of Rho that are inactivated by C3 but not by Y27632. Rho signals not only to
Figure 2. Axon regeneration after SCI and treatment with $\mathrm{C} 3$. Shown are dark-field micrographs of spinal cord sections; rostral is to the left. A, Anterogradely labeled CST fibers in a C3-treated spinal cord 3 weeks after injury. The lesion site is between the dotted lines. $B$, Same section as $A 12 \mathrm{~mm}$ caudal to the lesion site. $C$, Higher magnification of boxed region in $A$ to show regenerative sprouting into lesion site and into the dorsal white matter. $D$, A different section from the same animal as $A$, showing regenerating fibers $10 \mathrm{~mm}$ from the lesion site. $E$, Anterogradely labeled CST fibers 3 months after SCI sprout into the dorsal white matter and cross the lesion site. The lesion appears as a vertical line; accumulated blood contributes to the bright appearance of the lesion. $F$, Same section as $E$ taken $8 \mathrm{~mm}$ from the lesion site. $G$, Fibrin-treated control showing some sprouting of lesioned fibers, but no long-distance regeneration. $H$, Anterogradely labeled fibers retract from the lesion site in an untreated animal. $I$, Neutral red staining showing glial scar 1 month after lesion. Arrows indicate axon sprouting. Scale bars: $A, B, E, G, H$, $500 \mu \mathrm{m} ; I, 250 \mu \mathrm{m} ; C, D, 100 \mu \mathrm{m} ; F, 25 \mu \mathrm{m}$.

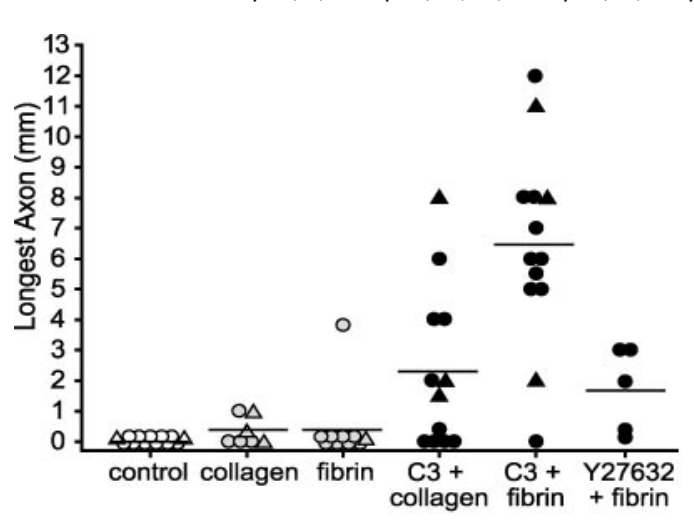

Figure 3. Quantification of regeneration length. Longest regeneration distances after SCI alone or treatment with vehicle, Rho antagonist C3, or Rho kinase inhibitor Y27632. Each point represents one animal. The circles represent animals examined 3 weeks to 1 month after SCI; the triangles represent animals examined at 3 months. Lines indicate averages for each group. Statistical significances were evaluated with the unpaired $t$ test: $\mathrm{C} 3+$ collagen versus collagen, $p<0.05$; $\mathrm{C} 3+$ fibrin versus fibrin, $p<0.001$; Y27632 + fibrin versus fibrin, $p<0.05$; $\mathrm{C} 3+$ collagen versus $\mathrm{C} 3+$ fibrin, $p<0.05 ; \mathrm{C} 3+$ fibrin versus Y27632 + fibrin, $p<0.01$. 

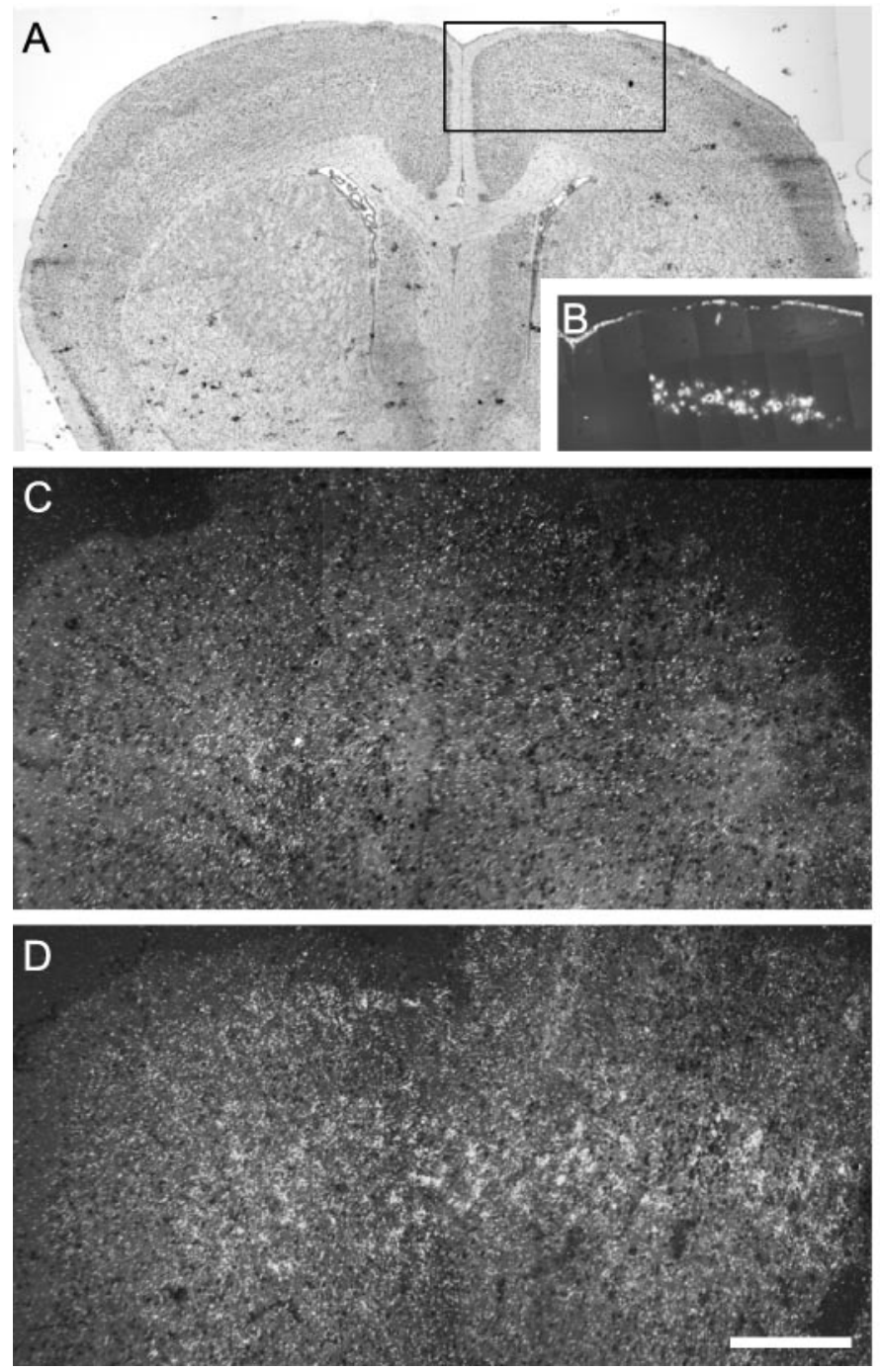

E

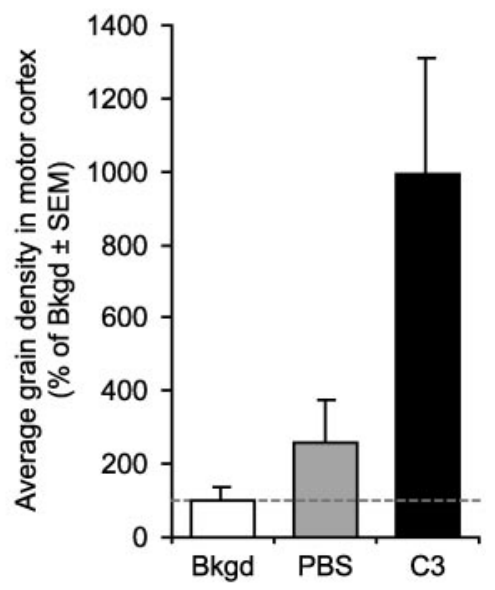

Figure 4. Expression of GAP-43 mRNA in motor cortex. $A$, Photomicrograph of a cresyl violet-stained coronal section of mouse brain. Box outlines motor cortex area depicted in $B-D$. $B$, Fluorescent micrograph of same section as in $A$ showing neurons retrogradely labeled with Fluorogold applied at the site of a dorsal hemisection at T7. $C, D$, Dark-field photomicrographs showing sections of motor cortex from an untreated mouse $(C)$ or a C3/fibrin-treated mouse $(D)$ after in situ hybridization for GAP-43. E, Quantitation showing significantly increased grain density in motor cortex after treatment with $\mathrm{C} 3$. Differences between $\mathrm{C} 3$ and background $(B k g d)$ were significant ( $t$ test; $p<0.05$ ); differences between PBS and background were not significant. Scale bar: $A, 1.8 \mathrm{~mm} ; B$, $1.2 \mathrm{~mm} ; C, D, 250 \mu \mathrm{m}$.
ROK but also to protein kinase N (Amano et al., 1996), rhotekin, and other targets (Reid et al., 1996). Therefore, for CNS repair, Rho appears to be a more efficient target than ROK.

The remarkable improvement in function within $1 \mathrm{~d}$ of spinal cord lesion and treatment with C3 or Y27632 may be caused by increased neuroprotection in the lesioned spinal cord. Neuroprotection by itself is important for improved functional recovery after SCI (Pencalet et al., 1993; Gaviria et al., 2000), and a growing volume of literature suggests that the application of $\mathrm{C} 3$ to ischemic CNS tissue has neuroprotective effects (Laufs et al., 2000; Trapp et al., 2001). Moreover, inactivation of Rho in spinal cord reduces the number of apoptotic cells (C. Dubreuil, M. Winton, F. Yang, P. Morley, and L. McKerracher, unpublished observations). It has been demonstrated that the application of C3 after middle cerebral artery occlusion reduces infract volumes (Trapp et al., 2001). Therefore, Rho signaling pathway is a good target to both prevent cell death and stimulate regeneration. The ability of C3 and Y27632 to block unwanted effects of Rho activation, cell death, and neurite retraction are likely to contribute importantly to improved outcome after SCI. It is also possible that C3 and Y27632 treatments affected other cells, such as leukocytes; immediate improvement in functional recovery after SCI has been observed $24 \mathrm{hr}$ after treatment with gabexate mesilate, a protease inhibitor that inhibits activation of leukocytes
(Taoka et al., 1997). Therefore, the short-term effects that we observe after treatment with C3 or Y27632 are likely caused by the ability of these compounds to limit the cell damage that occurs immediately after injury.

It should be kept in mind that mice show important differences from rats in their response to spinal cord injury, most notably the absence of necrotic cavitation (Steward et al., 1999). In our experiments, we used an over-hemisection of the spinal cord to test whether Rho or ROK inactivation was able to promote repair. Many strategies that work well to promote regeneration after hemisection are not effective after complete transection of the spinal cord. It has been shown that sparing of ventrolateral fibers may translate into improved locomotor performance (Brustein and Rossignol, 1998) because these fibers are important in the initiation and control of spinal central pattern generators (for review, see Rossignol et al., 2000). Sprouting of uninjured collaterals (Weidner et al., 2001) or sprouting of fibers that are part of the circuitry of the spinal cord (Giménez y Ribotta, 2000) are likely to contribute importantly to repair. It was demonstrated recently that reorganization of spared pathways also contributes to functional recovery (Raineteau et al., 2001). Thus, inactivation of Rho may help stimulate and enhance the spontaneous repair process that leads to limited recovery after SCI, in addition to its effects on regeneration. 
A

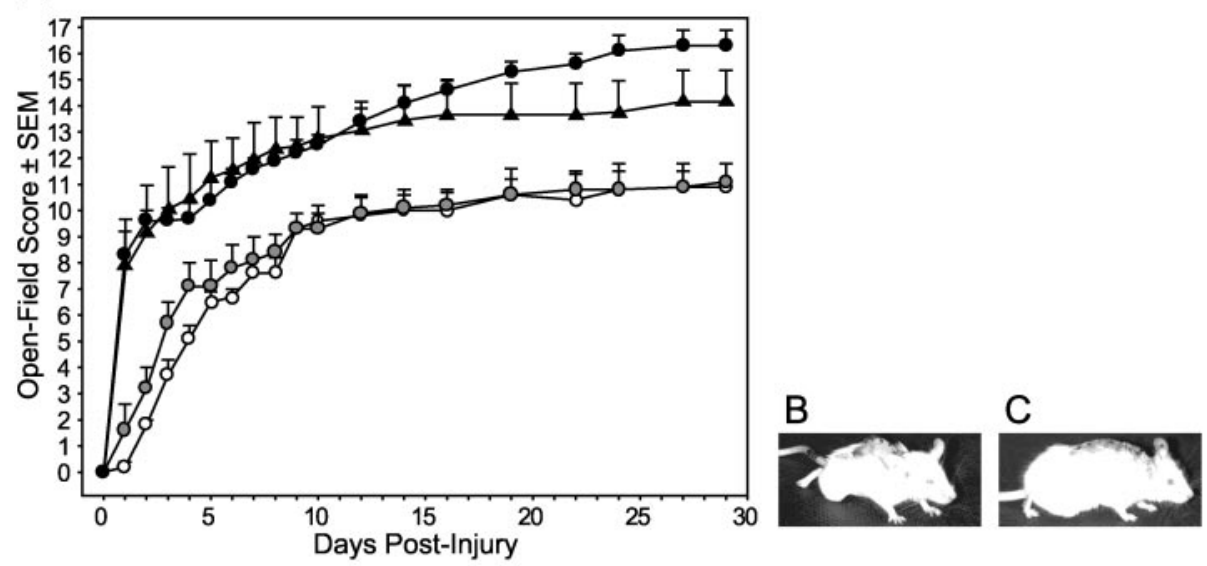

Figure 5. Analysis of functional recovery. $A$, Modified BBB scores of C3-treated (black circles; $n=11$ ), Y27632-treated (black triangles; $n=5$ ), fibrin-treated ( gray circles; $n=11$ ), and untreated (open circles; $n=10$ ) mice to evaluate recovery of locomotion during the month after dorsal over-hemisection. At $24 \mathrm{hr}, 1$ week, 2 weeks, and 1 month, differences between groups of animals were evaluated by the Mann-Whitney $U$ test. $p$ values were similar at all four time points: C3-treated versus fibrin-treated, $p<$ 0.001; Y27632-treated versus fibrin-treated, $p<$ 0.05; C3-treated versus Y27632-treated, NS; fibrin-treated versus untreated, NS. $B$, Photograph of a spinal cord-injured mouse $24 \mathrm{hr}$ after injury; HL cannot support body weight. $C$, Photograph of a C3/fibrin-treated mouse $24 \mathrm{hr}$ after injury; body weight is supported by HL. $D, E$, Selected videoframes of representative untreated and C3/fibrin-treated mice, respectively, to show differences in recovery of HL-FL coordination $30 \mathrm{~d}$ after lesion. Although C3-treated mice alternate front paw and foot placements properly, untreated mice do not show one-toone correspondence between HL and FL stepping. Numbers refer to elapsed time in tenths of seconds. $F, G$, For the mice depicted in $D$ and $E$, respectively, HL-FL coordination is represented graphically. The position of the right hindpaw (solid line) and the right front paw (dotted line) on $(I)$ or off $(O)$ the ground was noted for each 1 of 38 sequential videoframes. The untreated mouse in $D$ moves its forelimb twice before each HL step. NS, Not significant.

To study the effects of C3 and Y27632 on axons in vivo, we chose to study the CST because it is one of the best characterized tracts for studies of axon regeneration in the spinal cord. Moreover, the CST can be anterogradely labeled, and in mice, most of the fibers within the CST are located just above the central canal in the dorsal spinal cord. The dorsal over-hemisection that we used for our studies would eliminate not only the CST fibers but also other dorsal and lateral descending pathways while sparing the ventral pathways essential for locomotion. We demonstrated with our in vitro studies that treatment with C3 or Y27632 can stimulate axon growth on inhibitory substrates. In vivo, we observed sprouting and long-distance regeneration. It is well documented that reorganization of collateral CST fibers occurs after SCI (Weidner et al., 2001). Also, dendritic remodeling of neurons can be enhanced by inactivation of Rho (Ruchhoeft et al., 1999). Thus, inactivation of Rho, which is known to affect both axons and dendrites, is likely to enhance spontaneous plasticity of axons and dendrites, leading to functional remodeling of spinal cord circuitry.

The BBB open-field locomotor test cannot be correlated with the regeneration of specific tracts. Although the late recovery of HL-FL coordination that we observe at 1 month is consistent with regeneration of cut fibers, we cannot completely rule out the possibility of protective sparing, as reported with other strategies that promote repair after CNS injury (Lazarov-Spiegler et al., 1996; Hauben et al., 2000). However, our observation that GAP-43 is upregulated in the motor cortex is consistent with the interpretation that anterogradely labeled CST fibers past the injury site represent regenerated fibers. Increased GAP-43 expression correlates with regeneration of rubrospinal neurons, and projection neurons do not express GAP-43 after thoracic injury alone (Ferandes et al., 1999). Therefore the upregulation of GAP-43 expression is a good indicator for long-distance regeneration. We observed long-term improvements in BBB outcomes, even in animals in which substantial CST labeling was not observed. Therefore, many factors (neuroprotection, remodeling, and regeneration) and many fiber tracts (dorsal and ventral) are likely to contribute to functional recovery after SCI and treatment with Rho or Y27632. Notwithstanding the possibility of multiple mechanisms, long-distance regeneration is likely to have been important for the improved function at later stages. These treatments that potentiate spontaneous functional recovery in open-field tests give hope that effective treatment for spinal cord injury will be developed in the foreseeable future. The treatment that we have developed to promote functional recovery and axonal regeneration after SCI is simple: an inhibitor of Rho signaling pathway injected at the lesion site in a tissue adhesive. These studies show the potential for a new, straightforward treatment to reduce functional impairment after SCI.

\section{REFERENCES}

Amano M, Mukai H, Ono Y, Chihara K, Matsui T, Hamajima Y, Okawa K, Iwamatsu A, Kaibuchi K (1996) Identification of a putative target for Rho as the serine-threonine kinase protein kinase N. Science 271:648-650.

Asher RA, Morgenstern DA, Fidler PS, Adcock KH, Oohira A, Braistead JE, Levine JM, Margolis RU, Rogers JH, Fawcett JW (2000) 
Neurocan is upregulated in injured brain and in cytokine-treated astrocytes. J Neurosci 20:2427-2438.

Basi GS, Jacobson RD, Virag I, Schilling J, Skene JH (1987) Primary structure and transcriptional regulation of GAP-43, a protein associated with nerve growth. Cell 49:785-791.

Basso DM, Beattie MS, Bresnahan JC (1995) A sensitive and reliable locomotor rating scale for open filed testing in rats. J Neurotrauma 12:1-21.

Bito H, Furuyaashiki T, Ishihara H, Shibasaki Y, Ohashi K, Mizuno K, Maekawa M, Ishizaki T, Nurumiya S (2000) A critical role for a Rho-associated kinase, p160ROCK, in determining axon outgrowth in mammalian CNS neurons. Neuron 26:431-441.

Blesch A, Tuszynski MH (1997) Robust growth of chronically injured spinal cord axons induced by grafts of genetically modified NGFsecreting cells. Exp Neurol 148:444-452.

Bregman BS, Broude E, McAtee M, Kelleey MS (1998) Transplants and neurotrophic factors prevent atrophy of mature CNS neurons after spinal cord injury. Exp Neurol 149:13-27.

Broude E, McAtee M, Kelley MS, Bregman BS (1999) Fetal spinal cord transplants and exogenous neurotrophic support enhance c-Jun expression in mature axotomized neurons after spinal cord injury. Exp Neurol 155:65-78.

Brustein E, Rossignol S (1998) Recovery of locomotion after ventral and ventrolateral spinal lesions in the cat. I. Deficits and adaptive mechanisms. J Neurophysiol 80:1245-1267.

Cai D, Shen Y, DeBellard ME, Tang S, Filbin MT (1999) Prior exposure to neurotrophins blocks inhibition of axonal regeneration by MAG and myelin via a cAMP-dependent mechanism. Neuron 22:89-101.

Cai D, Qiu J, Cao Z, McAtee M, Bregman BS, Filbin MT (2001) Neuronal cyclic AMP controls the developmental loss in ability of axons to regenerate. J Neurosci 21:4731-4739.

Caroni P, Schwab ME (1988) Two membrane protein fractions from rat central myelin with inhibitory properties for neurite growth and fibroblast spreading. J Cell Biol 106:1281-1288.

Chen MS, Huber AB, van der Haar M, Frank M, Schnell L, Spillmann AA, Christ F, Schwab ME (2000) Nogo-A is a myelin-associated neurite outgrowth inhibitor and an antigen for monoclonal antibody IN-1. Nature 403:434-438.

Cheng H, Cao Y, Olson L (1996) Spinal cord repair in adult paraplegic rats: partial restoration of hind limb function. Science 273:510-513.

Coumans JV, Lin TT, Dai HN, MacArthur L, McAtee M, Nash C, Bregman BS (2001) Axonal regeneration and functional recovery after complete spinal cord transection in rats by delayed treatment with transplants and neurotrophins. J Neurosci 21:9334-9344.

Davies SJA, Goucher DR, Doller C, Silver J (1999) Robust regeneration of adult sensory axons in degenerating white matter of the adult rat spinal cord. J Neurosci 19:5810-5822.

Dillon ST, Feig LA (1995) Purification and assay of recombinant C3 transferase. Toronto: Academic.

Ferandes KJ, Fan DP, Tsui BJ, Cassar SL, Tetzlaff W (1999) Influence of the axotomy to cell body difference in rat rubrospinal and spinal motoneurons: differential regulation of GAP-43, tubulins and neurofilament-M. J Comp Neurol 414:495-510.

Fournier AE, Beer J, Arregui CO, Essagian C, Aguayo AJ, McKerracher L (1997) Brain-derived neurotrophic factor modulates GAP-43 but not $\mathrm{T} \alpha 1$ expression in injured retinal ganglion cells of adult rats. J Neurosci Res 47:561-572.

Gaviria M, Privat A, d'Arbigny P, Kamenka JM, Haton H, Ohanna F (2000) Neuroprotective effects of gacyclidine after experimental photochemical spinal cord lesion in adult rats: dose-window and timewindow effects. J Neurotrauma 17:19-30.

Giménez y Ribotta M, Provencher J, Feraboli-Lohnherr D, Rossignol S, Privat A, Orsal D (2000) Activation of locomotion in adult chronic spinal rats is achieved by transplantation of embryonic raphe cells reinnervating a precise lumbar level. J Neurosci 20:5144-5152.

Hall A (1998) Rho GTPases and the actin cytoskeleton. Science 279:509-514.

Hauben E, Nevo U, Yoles E, Moalem G, Agranov E, Mor F, Akselrod S, Neeman M, Cohen IR, Schwartz M (2000) Autoimmune T cells as potential neuroprotective therapy for spinal cord injury. Lancet 355:286-287.

Herbert CB, Nagaswami, C, Bittner GD, Hubbell (1998) Effects of fibrin micromorphology on neurite growth from dorsal root ganglia cultured in three-dimensional fibrin gels. J Biomed Mater Res 40:551-559.

Howland DR, Bregman BS, Tessler A, Goldberger ME (1995) Transplants enhance locomotion in neonatal kittens whose spinal cords are transected: a behavioral and anatomical study. Exp Neurol 135:123-145.

Huang DW, McKerracher L, Braun P, David S (1999) A therapeutic vaccine approach to stimulate axon regeneration in the adult mammalian spinal cord. Neuron 24:639-647.

Ishizaki T, Naaito M, Fujisawa K, Maekawa M, Watanabe N, Saito Y, Narumiya S (1997) p160ROCK, a Rho-associated coiled-coil forming protein kinase, works downstream of Rho and induces focal adhesions. FEBS Lett 404:118-124.
Jin Z, Strittmatter SM (1997) Rac1 mediates collapsin-1-induced growth cone collapse. J Neurosci 17:6256-6263.

Joosten EAJ, Bar PR, Gispen WH (1995) Collagen implants and corticospinal axonal growth after mid-thoracic spinal cord lesion in the adult rat. J Neurosci Res 41:481-490.

Katoh H, Aoki J, Ichikawa A, Negishi M (1998) p160 RhoA-binding kinase ROK $\alpha$ induces neurite retraction. J Biol Chem 273:2489-2492.

Kobayashi NR, Fan J, Giehl KM, Bedard AM, Weigand SJ, Tetzlaff W (1997) BDNF and NT-4/5 prevent atrophy of rat rubrospinal neurons after cervical axotomy, stimulate GAP-43 and T $\alpha 1$ tubulin mRNA expression, and promote axonal regeneration. J Neurosci 17:9583-9595.

Kuhn TB, Brown MD, Wilcox CL, Raper JA, Bamburg JR (1999) Myelin and collapsin-1 induce motor neuron growth cone collapse through different pathways: inhibition of collapse by opposing mutants of Rac1. J Neurosci 19:1965-1975.

Laufs U, Endres M, Stagliano N, Amin-Hanjani S, Chui DS, Yang SX Simoncini T, Yamada M, Rabkin E, Allen PG, Huang PL, Bohm M Schoen FJ, Moskowitz MA, Liao JK (2000) Neuroprotection mediated by changes in the endothelial actin cytoskeleton. $\mathrm{J} \mathrm{Clin}$ Invest 106:15-24.

Lazarov-Spiegler O, Solomon A, Zeev-Bran AB, Hirschberg DL, Lavie V, Schwartz M (1996) Transplantation of activated macrophages overcomes central nervous system regrowth failure. FASEB J 110:1296-1302.

Lehmann M, Fournier A, Selles-Navarro I, Dergham Selles-Navarro, Sebok A, Leclerc N, Tigyi G, McKerracher L (1999) Inactivation of Rho signaling pathway promotes CNS axon regeneration. J Neurosci 19:7537-7547.

Li D, Field PM, Raisman G (1995) Failure of axon regeneration in postnatal rat entorhinohippocampal slice coculture is due to maturation of the axon, not that of the pathway or target. Eur J Neurosci 7:1164-1171.

Li M, Shibata A, Li C, Braun Li, McKerracher L, Roder J, Kater SB, David S (1996) Myelin-associated glycoprotein inhibits neurite/axon growth and causes growth cone collapse. J Neurosci Res 46:404-414.

Liu A, Cerniglia GJ, Bernhard EJ, Prendergast GC (2001) RhoB is required to mediate apoptosis in neoplastically transformed cells after DNA damage. Proc Natl Acad Sci USA 98:6192-6197.

Liu Y, Kim D, Himes BT, Chow SY, Schallert T, Murray M, Tessler A, Fischer I (1999) Transplants of fibroblasts genetically modified to express BDNF promote regeneration of adult rat rubrospinal axons and recovery of forelimb function. J Neurosci 19:4370-4387.

McDonald JW, Lui X-Z, Qu Y, Liu S, Mickey SK, Turetsky D, Gottlieb DI, Choi DW (1999) Transplanted embryonic stem cells survive, differentiate and promote recovery in injured rat spinal cord. Nat Med 12:1410-1412.

McKeon RJ, Schreiber RC, Rudge JS, Silver J (1991) Reduction of neurite outgrowth in a model of glial scarring following CNS injury is correlated with the expression of inhibitory molecules on reactive astrocytes. J Neurosci 11:3398-3411.

McKerracher L, David S, Jackson JL, Kottis V, Dunn R, Braun PE (1994) Identification of myelin-associated glycoprotein as a major myelin-derived inhibitor of neurite outgrowth. Neuron 13:805-811.

Moon LD, Brecknell JE, Franklin RJ, Dunnett SB, Fawcett JW (2000) Robust regeneration of CNS axons through a track depleted of CNS glia. Exp Neurol 161:49-66.

Mukhopadhyay G, Doherty P, Walsh FS, Crocker PR, Filbin MT (1994) A novel role for myelin-associated glycoprotein as an inhibitor of axonal regeneration. Neuron 13:805-811.

Pencalet P, Ohanna F, Poulat P, Kamenka JM, Privat A (1993) Thienylphencyclidine protection for the spinal cord of adult rats against extension of lesions secondary to a photochemical injury. J Neurosurg 78:603-609.

Raineteau O, Fouad K, Noth P, Thallmair M, Schwab ME (2001) Functional switch between motor tracts in the presence of the mAb IN-1 in the adult rat. Proc Natl Acad Sci USA 98:6929-6934.

Ramon-Cueto A, Cordero MI, Santos-Benito FF, Avila J (2000) Functional recovery of paraplegic rats and motor axon regeneration in their spinal cords by olfactory ensheathing glia. Neuron 25:425-435.

Rapalino O, Lazarov-Spiegler O, Agranov E, Velau GJ, Yoles E, Fraidakis M, Solomon A, Gepstein R, Katz A, Belkin M, Hadani M, Schwartz M (1998) Implantation of stimulated homologous macrophages results in partial recovery of paraplegic rats. Nat Med 4:814-821.

Reid T, Furuyashiki T, Ishizaki T, Watanabe G, Watanabe N, Fujisawa K, Morii N, Madaule P, Narumiya S (1996) Rhotekin, a new putative target for Rho bearing homology to a serine/threonine kinase, PKN, and rhophilin in the rho-binding domain. J Biol Chem 271:13556-13560.

Rossignol S, Bélanger M, Chau C, Giroux N, Brustein E, Bouyer L, Grenier C-A, Drew T, Barbeau H, Reader T (2000) The spinal cat. In: Neurobiology of spinal cord injury (Kalb RG, Strittmatter SM, eds), pp 57-87. Totowa, NJ: Humana.

Ruchhoeft ML, Ohnuma S-I, Holt CE, Harris W (1999) The neuronal architecture of Xenopus retinal ganglion cells is sculpted by Rho-family GTPases in vivo. J Neurosci 19:8454-8463.

Sawai H, Clarke DB, Kittlerova P, Bray GM, Aguayo AJ (1996) Brain- 
derived neurotrophic factor and NT-4/5 stimulate the growth of axonal branches from regenerating retinal ganglion cells. J Neurosci 16:3887-3894.

Schnell L, Schwab ME (1990) Axonal regeneration in the rat spinal cord produced by an antibody against myelin-associated neurite growth inhibitors. Nature 343:269-272.

Schnell L, Schneider R, Kolbeck R, Barde Y-A, Schwab ME (1994) Neurotrophin-3 enhances sprouting of corticospinal tract during development and after adult spinal cord lesion. Nature 367:170-173.

Sekine A, Fujiwara M, Narumiya S (1989) Asparagine residue in the rho gene product is the modification site for botulinum ADPribosyltransferase. J Biol Chem 264:8602-8605.

Shen S, Wiemelt AP, McMorris A, Barres BA (1999) Retinal ganglion cells lose trophic responsiveness after axotomy. Neuron 23:285-295.

Snow DM, Lemmon V, Carrino DA, Caplan AI, Silver J (1990) Sulfated proteoglycans in astroglial barriers inhibit neurite outgrowth in vitro. Exp Neurol 109:111-130.

Steward O, Schauwecker PE, Guth L, Zhang Z, Fujiki M, Inman D, Wrathall J, Kempermann G, Gage FH, Saatman KE, Raghupathi R, McIntosh T (1999) Genetic approaches to neurotrauma research: opportunities and potential pitfalls of murine models. Exp Neurol 157:19-42.

Taoka Y, Okajima K, Uchiba M, Murakami K, Kushimoto S, Johno M, Naruo M, Okabe H, Takatsuki K (1997) Gabexate mesilate, a synthetic protease inhibitor, prevents compression-induced spinal cord injury by inhibiting activation of leukocytes in rats. Crit Care Med 25:874-879.

Tigyi G, Fischer DJ, Sebok A, Yang C, Dyer DL, Miledi R (1996) Lysophosphatidic acid-induced neurite retraction in PC12 cells: control by phosphoinositide- $\mathrm{Ca}^{+2}$ signaling and Rho. J Neurochem 66:537-548.

Trapp T, Olah L, Holker I, Besselmann M, Tiesler C, Maeda K, Hossmann KA (2001) GTPase RhoB: an early predictor of neuronal death after transient focal ischemia in mice. Mol Cell Neurosci 17:883-894.

Uehata M, Ishizaki T, Satoh H, Ono T, Kawahara T, Morishita T, Tamakawa H, Yamagami K, Inui J, Maekawa M, Narumiya S (1997) Calcium sensitization of smooth muscle mediated by a Rho-associated protein kinase in hypertension. Nature 389:990-994.

Wahl S, Barth H, Coiossek T, Akoriess K, Mueller BK (2000) Ephrin-A5 induces collapse of growth cones by activating Rho and Rho kinase. J Cell Biol 149:263-270.

Weidner N, Blesch A, Grill RJ, Tuszynski MH (1999) Nerve growth factor-hypersecreting Schwann cell grafts augment and guide spinal cord axonal growth and remyelinate central nervous system axons in a phenotypically appropriate manner that correlates with expression of L1. J Comp Neurol 413:495-506.

Weidner N, Ner A, Salimi N, Tuszynski MH (2001) Spontaneous corticospinal axonal plasticity and functional recovery after adult central nervous system injury. Proc Natl Acad Sci USA 98:3513-3518. 